\title{
Crioprotetores para o resfriamento de embriões de piracanjuba Brycon orbignyanus (Valenciennes, 1850)
}

\section{Cooling protocol for embryos of piracanjuba Brycon orbignyanus (Valenciennes, 1850)}

\author{
Darci Carlos Fornari ${ }^{1 *}$; Danilo Pedro Streit $\mathrm{Jr}^{2}$; Laura Botta Tonissi ${ }^{3}$; \\ Jayme Aparecido Povh"; Rodolfo Nardez Sirol ${ }^{5}$; Ricardo Pereira Ribeiro ${ }^{6}$
}

Resumo

O objetivo deste trabalho foi avaliar a eficiência dos crioprotetores para o resfriamento de embriões de B. orbignyanus. Foram selecionados 1.400 embriões viáveis, na fase de pós-gastrulação e submetidos ao resfriamento a $-8^{\circ} \mathrm{C}$ com diferentes combinações de crioprotetores permeáveis (Metanol e dimetilsulfóxido - DMSO $9 \%$ ou associados 4,5\%) combinados à crioprotetores não permeáveis (Sacarose e Glicose, 17\%). Para cada tratamento, 200 embriões foram alocados em tubos de vidro "vacutainer" e submetidos ao processo de resfriamento. Após o tempo proposto, os embriões foram retirados e transferidos para incubadoras de quatro litros até a eclosão das larvas. Os resultados com as soluções contendo glicose no resfriamento foram ineficiente, apenas $27 \%$ dos embriões sobreviveram no tratamento. Os tratamentos com associação do DMSO não houve sobrevivência. Para o resfriamento de embriões de $B$. orbignyanus exposto a $-8^{\circ} \mathrm{C}$ por um período de seis horas deve-se utilizar solução crioprotetora contendo sacarose $17 \%$ associada ao metanol $9 \%$.

Palavras-chave: Biotecnologia, criopreservação, crioprotetor, metanol, sacarose

\begin{abstract}
The aim of this study was to evaluate cryoprotectants for cooling embryos of B. orbignyanus. 1400 embryos were selected, in the post-gastrulation and subjected to cooling to $-8^{\circ} \mathrm{C}$ with different combinations of intracellular cryoprotectants (methanol and 9\% DMSO or associated 4.5\%) combined with extracellular cryoprotectants (sucrose and glucose, 17\%) diluted in distilled water to complete $100 \%$. For each treatment, 200 embryos were placed in glass tubes and submitted to the cooling process. After the proposed time, the embryos were removed and transferred to four-liter incubation to hatching of the larvae. The results obtained from solutions containing glucose were inefficient. The treatments with association of DMSO showed no satisfactory results. For cooling of B. orbignyanus embryos at $-8^{\circ} \mathrm{C}$ it is suggested to use a cryoprotectant solution containing $17 \%$ sucrose associated with $9 \%$ methanol.
\end{abstract}

Key words: Biotechnology, cryopreservation, cryoprotectant, methanol, sucrose

\footnotetext{
${ }^{1}$ Discente de Pós-Doutorado na Universidade Federal do Rio Grande do Sul, UFRGS, Porto Alegre, RS. E-mail: darci.peixegen@ gmail.com

${ }^{2}$ Prof., Universidade Federal do Rio Grande do Sul, UFRGS, Porto Alegre, RS. E-mail: danilo.streit@ufrgs.br

${ }^{3}$ Zootecnista, profissional liberal, Sorriso, MT. E-mail: laura tonissi@hotmail.com

${ }^{4}$ Prof., Universidade Federal do Mato Grosso do Sul, UFMS, Campo Grande, MS. E-mail: jayme.peixegen@gmail.com

${ }^{5}$ Diretor Ambiental, Companhia Paulista de Força e Luz, CPFL, Campinas, SP. E-mail: rnsirol@cpfl.com.br

${ }^{6}$ Prof. Associado do Dept ${ }^{\circ}$ de Zootecnia da Universidade Estadual de Maringá, UEM, Maringá, PR. E-mail: rpribeiro@uem.br

* Autor para correspondência
} 


\section{Introdução}

A criopreservação de embriões de peixes até o presente momento não é dominada, apesar de muitos esforços (HAGEDORN et al., 2004; ZHANG et al., 2007; LAHNSTEINER, 2008; FORNARI et al., 2010). No entanto, pesquisas sobre o resfriamento de embriões de algumas espécies são apresentados com bons resultados, sugerindo investigar novos protocolos de resfriamento para espécies ainda não estudadas (AHAMMAD; BHATTACHARYYA; JANA, 2002; STREIT JÚNIOR et al., 2007; FORNARI, et al., 2011; FORNARI et al., 2012). Através desta biotecnologia foi desenvolvido protocolos para preservar os embriões de algumas espécies há baixo metabolismo a tempo de resgatálos de lugares remotos, sincronizar lotes de diferentes desovas melhorando a eficiência nos laboratórios de reprodução, realizar o transporte dos embriões para laboratórios especializados a fim de desenvolver estudos específicos no embrião (STREIT JÚNIOR et al., 2004; AHAMMAD; BHATTACHARYYA; JANA, 2003),

Durante o resfriamento, as principais injúrias ocorrem quando a temperatura ultrapassa $0^{\circ} \mathrm{C}$. Esses danos morfológicos acontecem principalmente pela formação de cristais de gelo, no entanto, esses efeitos podem ser minimizados, quando os embriões de peixes são expostos aos crioprotetores (FORNARI et al., 2012). De acordo com Mazur (1977), ao submeter uma suspensão celular à temperatura ao redor de $-5^{\circ} \mathrm{C}$ contendo crioprotetores, tanto as células como o meio circundante sofrem um abaixamento do ponto de solidificação (formação de gelo), isso ocorre pela adição de substância crioprotetora à suspensão celular. $\mathrm{O}$ autor ainda atribuiu que na temperatura entre $-5 \mathrm{e}-15^{\circ} \mathrm{C}$ há maior propensão à formação dos cristais de gelo, tornando esta faixa de temperatura a mais critica durante o processo de congelamento. Dessa forma, faz-se importante os estudos em todas as etapas que envolve a rampa de congelamento no processo de criopreservação de embriões de peixes (REICHENBACH et al., 2001; FORNARI et al.,
2010).

Os crioprotetores são classificados de acordo com sua ação, intracelulares são os crioprotetores que permeiam as células chamados de permeáveis: metanol, etilenoglicol e DMSO (dimetilsulfóxido), e os de ação extracelular que não permeiam as células, conhecidos como não permeáveis: sacarose, glicose e trealose (DENNISTON; MICHELET; GODKE, 2000; NIEMANN, 1991; STREIT JÚNIOR et al., 2004). Os crioprotetores não permeáveis são basicamente açúcares com efeitos vantajosos em virtude do tamanho e composição de suas moléculas (NIEMANN, 1991; STREIT JÚNIOR et al., 2004). Segundo Denniston, Michelet e Godke (2000) o efeito do crioprotetor permeável é potencializado quando associado com um crioprotetor não permeável. Com base nesses trabalhos Streit Júnior et al. (2007) desenvolveram um experimento de resfriamento para embriões de Piaractus mesopotamicus, com eficiência de 69,2\% de eclosão utilizando solução crioprotetora contendo metanol (9\%) associado a sacarose (17\%) para o processo de resfriamento dos embriões $\left(-8^{\circ} \mathrm{C}\right)$. No entanto, a eficiência do processo de resfriamento de embriões de peixes poderá ser melhorada com a associação entre os crioprotetores permeáveis e não permeáveis, por apresentarem diferenças no peso molecular, toxidade e tamanho da molécula (ALI; SHELTON, 1993; DOBRINSKY, 2002).

Algumas espécies vêm sofrendo drástica redução dos seus estoques, em decorrência das construções e operacionalização de usinas hidroelétricas, poluições, devastação de matas ciliares, diminuição das lagoas marginais e pesca predatória (HAHN; FUGI, 2007). A piracanjuba B. orbignyanus, é uma espécie extremamente frágil às alterações ambientais, exemplares têm sido cada vez mais raramente capturados por pescadores, sendo considerada uma espécie em alto risco de extinção (GRAÇA; PAVANELLI, 2007). Na piscicultura, a $B$. orbignyanus tem seu destaque, sendo uma espécie muito apreciada em pescas esportivas, e de excelentes características organolépticas 
(URBINATI; GONÇALVES, 2005). É uma espécie reofílica, de desova total, e em piscicultura é de fácil obtenção de alevinos e possui hábito alimentar onívoro quando adulto (GRAÇA; PAVANELLI, 2007; NAKATANI et al., 2001).

O objetivo deste trabalho foi avaliar a eficiência dos crioprotetores no resfriamento de embriões de B. orbignyanus.

\section{Material e Métodos}

O experimento foi realizado na estação de Hidrologia e Aqüicultura da "Duke Energy" geração Paranapanema, Salto Grande, SP, durante os meses de dezembro a janeiro que envolve o período reprodutivo da espécie estudada.

Para obtenção dos embriões, foram utilizadas 10 fêmeas e 10 machos, com peso médio de 1,6 kg e $1,1 \mathrm{~kg}$, respectivamente. Para a seleção dos animais, verificou-se nas fêmeas: abdome abaulado e macio, papila urogenital saliente e avermelhada; e nos machos: liberação de sêmen com leve pressão no sentido encéfalo-caudal. Para maturação final dos gametas e desova, as fêmeas receberam dosagem de $5,5 \mathrm{mg} / \mathrm{Kg}$ de extrato hipofisário de carpa dividida em duas aplicações (10\% na primeira aplicação e $90 \%$ na segunda), com intervalo de 12 horas entre as injeções. Os machos receberam uma única dosagem (2,5 $\mathrm{mg} / \mathrm{Kg})$, coincidindo com a segunda dose das fêmeas.

Após indução hormonal os peixes foram transferidos para um tanque de desova seminatural. Este apresentava 5,1 $\mathrm{m}$ de raio, $1,85 \mathrm{~m}$ de profundidade média, fluxo de água contínuo de 131 $\mathrm{L} / \mathrm{s}$, e um cano de seis polegadas com a função de permitir o escoamento da água na porção central. Dessa forma, os ovos foram redirecionados pelo fluxo de água (7 L/s) para uma estação coletora. Os tanques foram cobertos com tela tipo sombrite $50 \%$ com intuito de minimizar estresse.

$\mathrm{Na}$ estação coletora, fora do laboratório, os embriões permaneceram contidos em incubadora cilindrico-cônica de 200 L, a qual recebeu os ovos provenientes do tanque circular. Em seguida, os embriões foram transportados para incubadoras do tipo Israel (7 L) dentro do laboratório. Estabeleceuse a retirada dos ovos da incubadora a cada hora, por um período de seis horas.

Após o fechamento do blastóporo, que ocorreu com seis horas de incubação, foram selecionados 1400 embriões viáveis (embriões com córion translúcido e morfologia visualmente intacta). Como grupo controle, 200 embriões foram alocados diretamente nas incubadoras até a eclosão. Os demais embriões foram submetidos às soluções contendo diferentes combinações de crioprotetores, externos (Glicose e sacarose) e internos (Metanol e DMSO). Para compor as soluções crioprotetoras, seguiu-se o protocolo sugerido por Streit Júnior et al. (2007) para embriões de P. mesopotamicus (Tabela 1). Com base nesse protocolo as soluções crioprotetoras foram distribuídas no volume de seis $\mathrm{ml}$, locadas em tubos de vidro (vacutainer), com duzentos embriões para cada tratamento (Tabela 1).

Adotou-se o método de resfriamento lento $\left(1^{\circ} \mathrm{C} /\right.$ minuto) utilizado por Ahammad, Bhattacharyya e Jana (2003) para embriões de Cyprinus carpio. Com exceção dos tubos contendo os embriões controle (que foram diretamente para incubadora), os demais, após serem vedados, foram colocados em água com gelo a temperatura de $15^{\circ} \mathrm{C}$ durante 10 min. Em seguida, transferidos para outro recipiente, também com água e gelo, a $5^{\circ} \mathrm{C}$ durante 10 minutos, e posteriormente colocados em refrigerador a $-8^{\circ} \mathrm{C}$ durante seis horas. 
Tabela 1. Composição das soluções crioprotetoras usadas no resfriamento de embriões de piracanjuba (Brycon orbignyanus).

\begin{tabular}{cccccc}
\hline \multirow{2}{*}{ TRATAMENTO } & \multicolumn{5}{c}{ CRIOPROTETOR $(\%)^{*}$ ÁGUA $^{(5)}$} \\
\cline { 2 - 5 } & SAC $^{(1)}$ & GLI $^{(2)}$ & MET $^{(3)}$ & DMSO $^{(4)}$ & \\
\hline T 1 & 17,1 & - & 9 & - & 73,9 \\
\hline T 2 & 17,1 & - & - & 9 & 73,9 \\
T 3 & 8,5 & 8,5 & 9 & - & 73,9 \\
T 4 & 8,5 & 8,5 & - & 9 & 73,9 \\
T 5 & 17,1 & - & 4,5 & 4,5 & 73,9 \\
T 6 & - & - & - & - & 100 \\
\hline
\end{tabular}

${ }^{1}$ sacarose, ${ }^{2}$ glicose,${ }^{3}$ metanol, ${ }^{4}$ dimetilsulfóxido, ${ }^{5}$ água destilada $(\mathrm{mL})$.

*Protocolo sugerido por Streit Júnior. et al. (2007).

Fonte: Elaboração dos autores.

Para o reaquecimento (momento de voltar os embriões na temperatura natural da água das incubadoras), os embriões foram colocados diretamente em incubadoras de $3 \mathrm{~L}$ (sem abrir os tubos) na temperatura de $27,1^{\circ} \mathrm{C}$, e após dois minutos (aclimatação), a solução crioprotetora foi desprezada e os embriões reidratados e liberados diretamente na água da incubadora, onde permaneceram até a eclosão. Após o período de desenvolvimento embrionário, quando se verificou a eclosão, as incubadoras foram esgotadas e determinadas o percentual de sobrevivência. A porcentagem de sobrevivência (taxa de eclosão) foi analisado através do Chi-quadrado com nível de significância de $1 \%$, na seguinte formula: $\chi^{2}=\Sigma\left[(\mathrm{o}-\mathrm{e})^{2} / \mathrm{e}\right]$. Onde: $\mathrm{o}=$ frequência observada; $\mathrm{e}=$ frequência esperada.

\section{Resultados e Discussão}

Após o período de estocagem a $-8^{\circ} \mathrm{C}$ observouse no tratamento sem crioprotetor (controle) grande quantidade de embriões esbranquiçados, evidenciando a formação de cristais de gelo, antes mesmo de retornarem à incubadora com renovação constante e temperatura média de $27,2^{\circ} \mathrm{C} \pm 0,2$. Nos tratamentos com solução crioprotetora não foi verificado coloração esbranquiçada, no entanto, a sobrevivência de embriões só foi verificada nos tratamentos contendo metanol associado à sacarose ou metanol associado à sacarose com glicose, o que comprova a eficiência do crioprotetor para submeter embriões à temperatura negativa. Embora não tenha ocorrido eclosão nos demais tratamentos, nos que continham DMSO, não foi verificado a formação de cristais de gelo. Neste caso, a ausência de eclosão pode estar relacionada à toxidade do DMSO para embriões desta espécie, quando associado à sacarose ou a glicose.

O resultado benéfico da associação dos crioprotetores metanol e sacarose (Tabela 2) está de acordo com os relatos apresentados por Streit Júnior et al. (2007), quando sugeriram como protocolo para $P$. mesopotamicus o uso de $17 \%$ de sacarose e $9 \%$ de metanol, para resfriamento durante seis horas a $-8^{\circ} \mathrm{C}$. O resultado satisfatório do presente estudo pode estar relacionado com a semelhança das duas espécies, que apresentam características reprodutivas e habitat semelhante, bem como características embrionárias, tamanho do ovo, compartimentalização do embrião e tempo de desenvolvimento embrionário (NAKATANI et al., 2001). O metanol associado com sacarose também foi observado por Ahammad, Bhattacharyya e Jana (1998), para o resfriamento de embriões de três espécies de carpa (Labeo rohita, Catla catla e Cirrhinus mrigala) quando estocaram a $-4^{\circ} \mathrm{C}$ com solução crioprotetora contendo 3,$2 ; 6,5$ e $9,7 \%$ de metanol e $17 \%$ de sacarose, concluindo que a 
adição de sacarose em soluções com metanol, foi fundamental para a sobrevivência dos embriões. Pesquisa realizada por Zhang e Rawson (1995) avaliando crioprotetores para embriões de Danio rerio, também sugeriram o uso de metanol associado com sacarose $(0,1 \mathrm{M})$. Outro trabalho que também corrobora com os resultados do presente experimento foi realizado com embriões de espécies sul americana por Fornari et al. (2013) que observaram eficiência do metanol associado a sacarose no resfriamento de embriões de Salminus brasiliensis.

Tabela 2. Índice de eclosão de larvas de Brycon orbignyanus após resfriamento por 6 horas a $-8^{\circ} \mathrm{C}$ usando diferentes crioprotetores.

\begin{tabular}{lcc}
\hline Tratamento & $\begin{array}{c}\text { Índice de } \\
\text { eclosão }\end{array}$ & $\begin{array}{c}\text { Taxa de eclosão } \\
(\%)\end{array}$ \\
\hline Controle (sem & $188 / 200 \mathrm{a}$ & $89 \mathrm{a}$ \\
resfriamento) & $164 / 200 \mathrm{~b}$ & $62 \mathrm{~b}$ \\
T1 & $0 / 200 \mathrm{~d}$ & $0 \mathrm{~d}$ \\
T2 & $54 / 200 \mathrm{c}$ & $27 \mathrm{c}$ \\
T3 & $0 / 200 \mathrm{~d}$ & $0 \mathrm{~d}$ \\
T4 & $0 / 200 \mathrm{~d}$ & $0 \mathrm{~d}$ \\
T5 & $0 / 200 \mathrm{~d}$ & $0 \mathrm{~d}$ \\
T6 (100\% de água) & \\
\hline
\end{tabular}

Valores seguidos de letras diferentes indicam diferença significativa pelo teste de $x^{2},(\mathrm{P}<0,01)$.

Fonte: Elaboração dos autores.

Um dos fatos que chama atenção e parece ser fundamental para a eficiência de soluções crioprotetoras na preservação de embriões de peixes em temperaturas negativas, é o uso de crioprotetores não permeáveis como é o caso dos açucares principalmente a sacarose, que promove uma estabilidade na solução crioprotetora. Os crioprotetores permeáveis e não permeáveis podem tornar-se tóxicos em função da sua concentração e o tempo de exposição (LAHNSTEINER, 2008). No presente experimento, o tempo de exposição aos crioprotetores foi de seis horas com $62 \%$ de sobrevivência quando expostos em solução contendo metanol e sacarose. Isso nos permite discutir os resultados de Woelders (1997) investigando células menores como sêmen de mamíferos, sobre o tempo de exposição das células a solução crioprotetora, antes mesmo de iniciar o processo de resfriamento, os açucares já apresentavam um papel importante, causando uma estabilidade na membrana celular, promovendo uma defesa adicional nas células, principalmente contra a ação dos crioprotetores permeáveis (influxo) e da água (efluxo) evitando deformações mecânicas da camada celular, e o tempo de exposição foi fundamental para o efeito positivo. Segundo Farkas et al. (2001), essa observação é evidenciada no que se refere à necessidade da manutenção da camada fosfolipídica, conferindo uma maior resistência tanto estrutural como funcional, quando exposta a uma nova temperatura. Além da proteção os açucares podem ter influência na pressão osmótica, conferindo um efeito tampão nas soluções crioprotetoras, agindo inclusive na possível oscilação de $\mathrm{pH}$ do meio (HOLT, 2000; JOHNSON, 2000).

Estes benefícios parecem melhorar quando se utiliza açucares de cadeias mais longas como é o caso da sacarose. É evidente ao compararmos com a glicose, que apresenta características parecidas, porém, tamanho molecular menor. Os resultados com glicose não foram satisfatórios no presente experimento. A substituição de 50\% da sacarose por glicose nas soluções com $9 \%$ de metanol não se mostraram apropriadas, com baixa taxa de eclosão. Segundo resultados obtidos por Streit Júnior et al. (2007) a substituição parcial da sacarose por glicose, quando associada ao metanol no resfriamento de embriões de $P$. mesopotamicus, não atuam efetivamente na proteção contra $o$ frio. A estrutura molecular da sacarose, que é um oligossacarídeo à confere um maior efeito de proteção do que açucares mais simples, além de provocar melhor desidratação dos embriões, evitando a formação de cristais de gelo (RALL, 1987) em temperaturas que se aproximam do ponto vítreo. 
O DMSO foi ineficiente como crioprotetor permeável no processo de resfriamento em embriões de Brycon orbignyanus, pois não ocorreu eclosão de larvas nos referidos tratamentos, nem mesmo quando se associou ao metanol, o que confere ao DMSO quando associado à sacarose ou glicose um efeito nocivo, nas condições utilizadas. Isso pode estar relacionado com a interferência que esse crioprotetor pode ter no metabolismo do embrião, provocando desestruturação celular e consequentemente a morte (KUSUDA; TERANISHI; KOIDE, 2002). O que também foi conferido por Adam, Rana e McAndrew (1995) que utilizaram como crioprotetores permeáveis DMSO e o etilenoglicol para embriões de "rosy barb" (Puntius conchonius) e zebrafish (Danio rerio) em quatro estádios de desenvolvimento, e observaram que os crioprotetores, mesmo em concentrações menores (em torno de $1 \mathrm{M}$ ), promoveram redução da atividade enzimática no embrião, levando a morte.

Os tratamentos que continham 9\% de metanol possibilitaram uma boa taxa de eclosão (62\%) dos embriões submetidos ao processo de resfriamento, onde possivelmente tenha provocado a desidratação sem apresentar toxidez aos embriões de $B$. orbignyanus, evitando a formação de cristais de gelo e deformação celular, como também foi ressaltado por Bart (2000), a eficiência do metanol em comparação aos outros crioprotetores permeáveis, que observou menor taxa de eclosão de larvas de Danio rerio em embriões conservados com DMSO, etilenoglicol e glicerol, todos na concentração de $40 \%$. Outro resultado que corrobora com o presente estudo, aconteceu em estudos de congelação de embriões de Danio rerio, onde o melhor resultado ocorreu quando se utilizou o metanol (ZHANG; RAWSON, 1995). Os autores encontraram maior eficiência do metanol em relação aos crioprotetores DMSO e propano-1,2 diol em embriões submetidos a baixas temperaturas $\left(0 ;-5 ;-10\right.$ e $\left.-15^{\circ} \mathrm{C}\right)$, porém a concentração do metanol precisou ser aumentada de $1 \mathrm{M}$ até $4 \mathrm{M}$ de acordo com o decréscimo da temperatura. Com espécies brasileiras Fornari et al., 2012 sugeriram o metanol associado a sacarose para o resfriamento a $-8^{\circ} \mathrm{C}$ de embriões de $P$. mesopotamicus. Baseado nos resultados, novos estudos com embriões de Brycon orbignyanus devem ser realizados a fim de se estabelecer um protocolo de resfriamento eficiente para a espécie.

\section{Conclusão}

O crioprotetor permeável metanol (9\%) com adição do não permeável sacarose $(17,1 \%)$ é indicado para estocar embriões de B. orbignyanus por um período de seis horas em temperaturas de $-8^{\circ} \mathrm{C}$.

\section{Agradecimentos}

Os autores agradecem Duke Energy geração Paranapanema, Salto Grande, SP pelo material e estrutura cedidos, ao CNPq pela concessão da bolsa de estudo para o autor.

\section{Referências}

ADAM, M. M.; RANA, K. J.; McANDREW, B. J. Effect of cryoprotectants on activity of selected enzymes in fish embryos. Cryobiology, San Diego, v. 32, n. 2, p. 92-104, 1995.

AHAMMAD, M. M.; BHATTACHARYYA, D.; JANA, B. B. Effect of different concentrations of cryoprotectant and extender on the hatching of Indian major carp embryos Labeo rohita, Catla catla, and Cirrhinus mrigala stored at low temperature. Cryobiology, San Diego, v. 37, n. 4, p. 318-324, 1998.

Hatching of common carp Cyprinus carpio L. embryo stored at 4 and $-2^{\circ} \mathrm{C}$ in different concentration of methanol and sucrose. Theriogenology, Stoneham, v. 60, n. 8, p. 1409-1422, 2003.

. The hatching of common carp (Cyprinus carpio L.) embryos in response to exposure to different concentrations of cryoprotectant at low temperatures. Cryobiology, San Diego, v. 44, n. 2, p. 114-121, 2002.

ALI, J.; SHELTON, J. N. Design of vitrification solutions for the cryopreservation of embryos. Journal of Reproduction and Fertilty, Terhran, v. 99, n. 2, p. 471477, 1993. 
BART, A. New approaches in cryopreservation of fish embryos. In: TIERSCH, T. R.; MAZIK, P. M. (Ed.). Cryopreservation in aquatic species. Baton Rouge: World Aquaculture Society, 2000. p. 179-187.

DENNISTON, R. S.; MICHELET, S.; GODKE, R. A. Principles of cryopreservation. In: TIERSCH, T. R.; MAZIK, P. M. (Ed.). Cryopreservation in aquatic species. Baton Rouge: World Aquaculture Society, 2000. p. $59-74$.

DOBRINSKY, J. R. Advancements in cryopreservation of domestic animal embryos. Theriogenology, Stoneham, v. 57, n. 5, p. 285-302, 2002.

FARKAS, T.; FODOR, E.; KITAJKA, K.; HALVER, J. E. Response of fish membranes to environmental temperature. Aquaculture Research, Oxford, v. 32, n. 8, p. $645-655,2001$.

FORNARI, D. C.; RIBEIRO, R. P.; STREIT JÚNIOR, D. P. GODOY, L.; NEVES, P.; SIROL, R. Effect of cryoprotectants on the survival of cascudo preto (Rhinelepis aspera) embryos stored at $-8 \circ \mathrm{C}$. Zygote, Cambrideg, v. 22, n. 1, p. 1-6, 2011.

FORNARI, D. C.; RIBEIRO, R. P.; STREIT JÚNIOR, D. P.; VARGAS, L.; GODOY, L.; OLIVEIRA, D.; DGMAYER, M.; GALO, J. M.; NEVES, P. Increasing storage capability of pacu (Piaractus mesopotamicus) embryos by chilling: development of a useful methodology for hatcheries management. Cryoletters, Norton, v. 33, n. 2, p. 125-133, 2012.

FORNARI, D. C.; RIBEIRO, R. P.; STREIT JÚNIOR, D. P.; VARGAS, L.; MORAES, V. G. Freezing injuries in the embryons of Piaractus mesopotamicus. Zygote, Cambrideg, v. 19, n. 4, p. 1-6, 2010.

FORNARI, D. C.; STREIT JÚNIOR, D. P.; GALO, M. J.; NEVES, P.; SIROL, R.; RIBEIRO, R. P.; Viability of dourado embryos cooled in different cryoprotectant solutions. Pesquisa Agropecuária Brasileira, Brasília, v. 48, n. 8, p. 1175-1178. 2013.

GRAÇA, W. J.; PAVANELLI, C. S. Peixes da planície de inundação do alto rio Paraná e áreas adjacentes. Maringá: EDUEM, 2007. 78 p.

HAGEDORN, M.; PETERSON, A.; MAZUR, P.; KLEINHANS, F. W. High ice nucleation temperature of zebrafish embryos: slow-freezing is not an option. Cryobiology, San Diego, v. 49, n. 2, p. 181-189, 2004.

HAHN, N. S.; FUGI, R. Alimentação de peixes em reservatórios brasileiros: alterações e consequências nos estágios iniciais do represam. Oecologia Brasiliensis, Rio de Janeiro, v. 11, n. 4, p. 469-480, 2007.

HOLT, W. V. Basic aspects of frozen storage of semen.
Animal Reproduction Science, Manchester, v. 62, n. 3, p. 3-22, 2000.

JOHNSON, L. A. Lessons from the cryopreservation of livestock sperm. In: TIERSCH, T. R.; MAZIK, P. M. (Ed.). Cryopreservation in aquatic species. Baton Rouge: World Aquaculture Society, 2000. p. 381-387.

KUSUDA, S.; TERANISHI, T.; KOIDE, N. Cryopreservation of chum salmon blastomeres by the straw method. Cryobiology, San Diego, v. 45, n. 1, p. 6067, 2002.

LAHNSTEINER F. The effect internal and external on zebrafish (Dario rerio) embryo. Theriogenology, Stoneham, v. 69, n. 8, p. 384-396, 2008.

MAZUR, P. The role intracellular freezing in the death of cells cooled at supraoptimal rates. Cryobiology, San Diego, v. 14, n. 3, p. 251-272, 1977.

NAKATANI, K.; AGOSTINHO, A. A.; BAUMGARTNER, G.; BIALETZKI, A.; SANCHES, P. V.; MAKRAKIS, M. C.; PAVANELLI, C. S. Ovos e larvas de peixes de água doce: desenvolvimento e manual de identificação. Maringá: EDUEM, 2001. 349 p.

NIEMANN, H. Cryopreservation of ova and embryos from livestock: current status and research needs. Theriogenology, Stoneham, v. 35, n. 1, p. 109-124, 1991.

RALL, W. F. Factors affecting the survival of mouse embryos cryopreserved by vitrification. Cryobiology, San Diego, v. 24, n. 5, p. 387-402, 1987.

REICHENBACH, H. D.; OLIVEIRA, L.; LIMA, P. F.; SANTOS-FILHO, A. S.; ANDRADE, J. C. O. Transferência e criopreservação de embriões bovinos. In: GONSALVES P. B.; FIGUEIREDO, J. R.; FREITAS, V. J. F. Biotécnicas: aplicação à reprodução animal. São Paulo: Ed. Varela, 2001. cap. 8, p. 127-178.

STREIT JÚNIOR, D. P.; DIGMAYER, M.; RIBEIRO, R. P.; SIROL, R.; MORAES, G. V.; GALO, J. M. Embriões de pacu submetidos a diferentes protocolos de resfriamento. Pesquisa Agropecuária Brasileira, Brasília, v. 42, n. 8, p. 1199-1202, 2007.

STREIT JÚNIOR, D. P.; RIBEIRO, R. P.; MORAES, G. V.; CAPOVILLA, L. C. Criopreservação de embriões de peixes. Revista Brasileira de Reprodução Animal, Belo Horizonte, v. 28, n. 1, p. 54-62. 2004.

URBINATI, E. C.; GONÇALVES, F. D. Pacu (Piaractus mesopotamicus). In: BALDISSEROTO, B.; GOMES, L. C. Espécies nativas para a piscicultura no Brasil. Santa Maria: UFSM, 2005. p. 225-246.

WOELDERS, H. Fundamentals and recent development in cryopreservation of bull and boar semen. The Veterinary Quarterly, London, v. 19, n. 3, p. 135-138, 1997. 
ZHANG, T.; RAWSON, D. M. Studies on chilling sensitivity of zebrafish (Brachydanio rerio) embryos. Cryobiology, San Diego, v. 32, n. 3, p. 239-246, 1995.
ZHANG, Y. Z.; ZHANG, S. C.; LIU, X. Z.; XU, Y. J.; HU, J. H.; XU, Y. Y.; LI, J. Chen SL. Toxicity and protective efficiency of cryoprotectants to flounder (Paralichthys olivaceus) embryos. Theriogenology, Stoneham, v. 63, $\mathrm{n}$. 3, p. 763-773, 2007. 